Cahiers $d u$ MONDE RUSSE

\section{Cahiers du monde russe}

Russie - Empire russe - Union soviétique et États indépendants

$62 / 4 \mid 2021$

Varia

\title{
Jörg BABEROWSKI, Der bedrohte Leviathan. Staat und Revolution in Rußland
}

\section{Gábor T. Rittersporn}

\section{(2) OpenEdition}

Journals

Édition électronique

URL : https://journals.openedition.org/monderusse/12822

DOI : 10.4000/monderusse. 12822

ISSN : $1777-5388$

Éditeur

Éditions de l'EHESS

Édition imprimée

Date de publication : 1 décembre 2021

Pagination : 710-714

ISBN : 978-2-7132-2895-7

ISSN : $1252-6576$

Référence électronique

Gábor T. Rittersporn, "Jörg BABEROWSKI, Der bedrohte Leviathan. Staat und Revolution in Rußland », Cahiers du monde russe [En ligne], 62/4 | 2021, mis en ligne le 01 décembre 2021, consulté le 03 septembre 2022. URL : http://journals.openedition.org/monderusse/12822 ; DOI : https://doi.org/ 10.4000/monderusse. 12822

Ce document a été généré automatiquement le 3 septembre 2022.

Tous droits réservés 


\title{
Jörg BABEROWSKI, Der bedrohte Leviathan. Staat und Revolution in $\mathrm{Ru}$ ßland
}

\author{
Gábor T. Rittersporn
}

\section{RÉFÉRENCE}

Jörg BABEROWSKI, Der bedrohte Leviathan. Staat und Revolution in Rußland, Berlin :

Duncker \& Humblot, 2021, $127 \mathrm{p}$.

1 La mauvaise presse de Carl Schmitt est justifiée. Son soutien au régime nazi est allé jusqu'à célébrer Hitler comme "juge suprême " et la législation raciste comme la " constitution de la liberté ». Les débats sur la question de savoir si et à quel point son enthousiasme s'inscrivait organiquement dans l'évolution de sa pensée ne sont pas près de finir. Toujours est-il que ses idées sur le pouvoir, sur le politique, sur l'État, sur la souveraineté ou sur les origines théologiques des concepts qui les concernent exercent une influence considérable. Si ces idées procèdent d'une vision conservatrice et antilibérale du monde, elles ne sont pas l'apanage des gardiens de traditions autoritaires. Par exemple, la revue Telos qui a commencé sa carrière en bonne élève de l'École de Francfort en 1968 et la poursuit jusqu'à nos jours sur cette lancée, joue un rôle éminent dans la réception américaine de l'œuvre de Schmitt depuis les années 1980.

Il est à craindre que quelques collègues ne soient tentés de bouder un livre fondé sur une conférence tenue à la Société Carl Schmitt et dont le titre fait habilement allusion à Lenin et, surtout, à la lecture schmittienne de l'enseignement de Hobbes sur l'utilité de bénéficier des décisions d'un souverain absolu et de la protection d'un État fort. L'auteur, Jörg Baberowski, a toutes les raisons de déclarer que celui qui refuse de se plonger dans un ouvrage dont il n'accepte pas les prémisses se prive de l'expérience de se découvrir soi-même dans le miroir tendu par un Autre. Outre le grand mérite de placer quelques événements clés de 1917 dans une perspective radicalement novatrice, son livre a tout 
pour confronter le lecteur aux idées reçues qui sous-tendent l'historiographie de la révolution russe et aux constructions dogmatiques qui en sont inséparables.

Le métier est seulement en train de se débarrasser de l'influence souterraine des œuvres de théoriciens classiques du socialisme et de discours sur la nécessité historique, sur la classe ouvrière ou sur les discussions des bolcheviks et de leurs rivaux, discours qui ne manquent pas d'affinités avec les exégèses militantes de toutes couleurs voire avec des schémas que les vainqueurs d'Octobre ont réussi à répandre. Et voici un historien qui ne fait pas grand cas des mouvements de masse et s'inspire des conceptions de Schmitt de la décision souveraine, de l'état d'urgence et d'un pouvoir qui ne peut être qu'autoritaire pour s'institutionnaliser. Il aggrave son cas en mettant l'accent sur la futilité des affaires de ce monde et sur la volonté telles qu'elles sont saisies par Nietzsche, sur la portée historique du hasard soulignée par Ortega y Gasset et par Isaiah Berlin ou en faisant appel à Tocqueville pour rendre compte du peu de choses que la révolution semble avoir changé aux paradigmes fondateurs de l'histoire russe.

Baberowski explique qu'en février 1917 le danger mortel pour l'Ancien Régime et pour le Gouvernement provisoire était l'absence de véritables décideurs déterminés à prendre des mesures énergiques pour écraser une émeute de la faim et s'imposer comme sujets historiques souverains. Les portes-drapeaux du camp des réformes libérales étaient propulsés à la tête d'un soulèvement dont ils ne voulaient pas, les chefs de l'armée voulaient préserver un statu quo ante impossible à sauver et les ennemis les plus résolus $\mathrm{du}$ vieil ordre étaient désorientés face à un bouleversement qu'ils souhaitaient ardemment mais qu'ils n'avaient pas anticipé. La situation continuait à dépasser les libéraux et les conservateurs alors que les révolutionnaires les plus radicaux pouvaient s'offrir le luxe d'attendre leur heure.

5 Le chef du gouvernement, Aleksandr Kerenskij, posait en dictateur sans être capable d'imposer un régime dictatorial. Pour Baberowski, les bolcheviks avaient toutes les raisons d'affirmer, après les événements, que le pouvoir était dans la rue et qu'ils ont pu le prendre tout simplement. Il argue que dans une situation pareille, les masses ne peuvent jamais agir sans meneurs et qu'elles deviennent une véritable puissance sous la direction d'un petit groupe de chefs qui sont prêts à tout et les plient à leurs stratégies. Lenin aurait pu manquer le moment décisif car il n'y avait aucune nécessité pressante qu'il le saisisse. Il fallait sa lucidité pour reconnaître l'instant prometteur, son audace pour lancer une action à l'issue incertaine, son absence de scrupules pour tenter un coup d'État et s'arroger un monopole politique ainsi que sa volonté de fer pour instaurer une dictature qui allait surprendre beaucoup de ses propres partisans.

La désintégration des institutions a garanti l'autorité d'un leader qui incarnait ce qu'elles ne pouvaient plus achever. L'ascendant du chef a compensé la disparition de l'ordre établi du régime déchu et l'échec des règles qu'il avait établies et préservées. Si bien que dans l'absence de pouvoirs légitimes de contrôle sur l'action du nouveau maître, celui-ci devait être accepté comme législateur suprême. Même si Baberowski condamne le leader révolutionnaire et ses successeurs, sa critique n'est pas étrangère à la vision de Schmitt du Führerprinzip au Troisième Reich. Mais il n'a pas l'intention d'assimiler l'État bolchevik à celui des nazis. Il s'intéresse aux sources, à l'établissement et au fonctionnement du pouvoir qui allait s'affirmer grâce au coup de force de Lenin et de ses troupes. Il parle d'un dictateur qui est à même de se substituer aux institutions même quand elles sont constituées et d'une dictature qu'on accepte car, si elle sait punir cruellement, elle apprend à gratifier ses sujets. Né d'un état d'urgence, l'État soviétique 
crée des états d'urgence quasi permanents après avoir vaincu sur les fronts de la guerre civile et brisé quelques révoltes populaires, en traquant des ennemis réels et imaginaires, en imposant des projets ambitieux aux conséquences imprévues, en tentant de mettre au pas les travailleurs des villes et des villages ainsi que ses propres représentants ou en déployant des campagnes de terreur déchaînée.

7 L'une des idées de Schmitt est la souveraineté de ceux qui peuvent faire en sorte que l'état d'urgence qu'ils décrètent soit observé. Poursuivant la conception jusqu'à son aboutissement logique, Baberowski montre que l'abandon du régime d'exception relevait également d'une décision souveraine d'une autorité suprême qui n'était plus celle d'un dictateur. Elle était prise à une période où les structures d'autorité de l'État soviétique étaient fermement établies et où il pouvait s'appuyer sur l'intériorisation par la population de ses normes et de traditions qu'il avait produites. Baberowski explique que ces traditions procédaient d'un long développement historique dont les origines remontent bien avant 1917, la crise du régime tsariste et à quelques égards même avant l'ère impériale. Il se demande si les bouleversements révolutionnaires et les événements tragiques qui s'ensuivirent étaient nécessaires pour en arriver là.

En lisant Baberowski on ne sait pas trop en quoi la révolution russe était différente des coups d'État qui émaillent l'histoire de l'Amérique latine. Aussi, peut-on réduire l'histoire soviétique aux agissements de chefs et d'un État, aussi autoritaire et puissant soit-il, et aux états d'urgence qu'il déclarait ? Certes, ces hypothèses sont tentantes.

Pour autant, on peut supposer également que les actions de l'État soviétique et ses leaders suprêmes étaient des réponses, le plus souvent démesurées, à l'exercice d'un pouvoir qui dépasse la portée des théories de Schmitt. En injectant dans l'interprétation schmittienne une dose des modèles de Michel Foucault, on peut constater que le pouvoir se déploie un peu partout dans la société où il s'agit de passer dans les faits des décisions prises au nom de l'État. Dans cette optique, on peut reconnaître que l'une des constantes de l'histoire soviétique était un conflit latent du régime avec lui-même et avec le reste de la société autour de la réalisation de décisions, programmes et plans.

Un pouvoir autoritaire qui veut dicter des projets qu'il a le monopole de lancer et qu'il interdit de contester est constamment confronté à l'incertitude quant à la mise en œuvre de ses politiques. Des sujets y compris des officiels qui, sans avancer des projets concurrents, évitent l'accomplissement de tâches, les contournent ou recourent à de petites tactiques illégales pour alléger leurs conditions de vie (à l'occasion, en tentant de modifier les rapports légitimes de propriété) interfèrent avec le monopole politique des décideurs et entament la souveraineté de l'État, surtout dans le cas où leurs pratiques sont répandues. Leurs actions deviennent des « institutions informelles » et révèlent que l'État et ses leaders sont parties prenantes d'un contexte social qu'ils ne contrôlent pas entièrement, malgré leur ambition de le dominer totalement.

Une révolution change fondamentalement les relations de force au sein d'une société. De ce point de vue, le coup d'État bolchevik qui n'a changé que de gouvernement est simple à analyser selon les axiomes de Schmitt et il est comparable à n'importe quel vulgaire putsch. Aussi, à cet égard la révolution de 1917 n'était ni socialiste, ni bolchevique, ni ouvrière, ni celle des soviets dont Marc Ferro a montré qu'ils sont vite devenus de simples administrations. Elle n'était même pas d'Octobre ou de Février. Elle a commencé avec l'occupation des terres par les paysans qui a démarré en avril. Sans se soucier de l'État ni des décisions de ceux qui le dirigeaient ou le représentaient, ils ont transformé 
rapidement les institutions des campagnes, dans la plupart des cas en établissant des formes archaïques de la gestion collective du village et de son économie.

En quelques mois, ils sont devenus arbitres de la situation politique en choisissant comme moindre mal les bolcheviks pendant la guerre civile et en décidant de l'alimentation du pays dans les années qui l'ont suivie, en commercialisant ou en retenant leurs produits en fonction de l'évolution des prix que les autorités fixaient. Ils étaient à même de déclencher des états d'exception sous la forme de crises d'approvisionnement jusqu'au moment où les bolcheviks ont pris la décision schmittienne d'imposer un état d'urgence plus radical que ceux des villageois en les privant du contrôle des terres et en les contraignant, manu militari, à se soumettre à l'État. Mais par la suite, aucun tyran ni aucun gouvernement magnanime ne put empêcher que, tout au long de l'ère soviétique, les stratégies de survie des paysans ne transforment l'agriculture en talon d'Achille du régime.

Les perspectives ouvertes par Carl Schmitt n'embrassent pas toutes les dimensions de la révolution russe et de l'État soviétique. Aucune théorie, aucune démarche ne pourraient le faire. Mais nous sommes redevables à Jörg Baberowski de son étude originale, brillante et, à sa façon, révolutionnaire des tenants et des aboutissants de la décision de Lenin de saisir le moment où les bolcheviks pouvaient dicter le cours des événements et jeter les fondements d'une dictature qui deviendra avec le temps un État autoritaire. Pour combler le plaisir intellectuel du lecteur, il accompagne son analyse historique de l'exposition des cadres conceptuels de sa démonstration qui fait preuve d'une grande culture philosophique. Le défi fascinant qu'il lance à nos schémas de pensée doit nous inciter à revenir sur la révolution russe, le coup de force bolchevik et leurs conséquences aussi bien que sur les idées et les idéaux qui sous-tendent notre vision traditionnelle.

\section{AUTEURS}

GÁBOR T. RITTERSPORN

CNRS - CERCEC 